\title{
Discussion on the ideal of program- correctness by Tony Hoare
}

Article

Published Version

Josephs, M. B., Jones, C., Jackson, M., Turner, A., Holcombe, M., Sharman, G., Luo, Z. H., Lloyd, M., Haworth, G. M., Tully, C. and Crocker, D. (2007) Discussion on the ideal of programcorrectness by Tony Hoare. Computer Journal, 50 (3). pp. 261 268. ISSN 0010-4620 doi:

https://doi.org/10.1093/comjnl/bxl079 Available at https://centaur.reading.ac.uk/15296/

It is advisable to refer to the publisher's version if you intend to cite from the work. See Guidance on citing.

To link to this article DOI: http://dx.doi.org/10.1093/comjnl/bx1079

Publisher: Oxford University Press

All outputs in CentAUR are protected by Intellectual Property Rights law, including copyright law. Copyright and IPR is retained by the creators or other copyright holders. Terms and conditions for use of this material are defined in the End User Agreement.

\section{www.reading.ac.uk/centaur}

\section{CentAUR}


Central Archive at the University of Reading

Reading's research outputs online 


\section{The Ideal of Program Correctness}

Third Computer Journal Lecture

TONY HOARE

\section{Discussion on The Ideal of Program Correctness by Tony Hoare}

\section{GUY HAWORTH}

School of Systems Engineering, University of Reading, UK. Email: g.haworth@ reading.ac.uk

(i) What examples are there of achievements in showing Program Correctness? Are any of these in a nondiscrete domain?

(I asked the speaker this after the meeting. He mentioned work done on the Ariane software system after the loss of a satellite. Since this software used floating-point numbers, we classify this as not being in a discrete domain.)

(ii) What are the leading methods and tools for Program Verification today?

\section{hrom}

The Computer Fournal, 50.3 (2007) pp. $254-260,261-268$

ance 269-273 (iii) It seems that if program $\mathrm{P}$ is to be formally verified from specification $S$, then $S$ (as well as $P$ ) are expressed in a formal language.

Working back, it seems that any formal verification must start with a formal statement in a formal language.

Therefore, all formal verification is done in a 'formal world' of formal statements and formal verification methods.

Since the room here is in two parts, let us designate that side of the room with Leading Computer Scientists in as 'the formal world'.

However, requirements for systems are originally expressed using informal, natural languages, such as English.

These languages are flexible and therefore have their ambiguities and dangers.

Further, at some point, there is a 'last' expression of requirements in natural language and a 'first' expression in a formal language.

It would seem impossible to do better than to have the translation of the one to the other signed off by a domain expert as no formal verification is possible. Is this a fair assessment of the situation?

\section{Discussion on The Ideal of Program Correctness: Responses from Tony Hoare}

\section{TO GUY HAWORTH}

(i) The answers to these questions may be found in a 'roadmap' document being assembled at http:// qpq.csl.sri.com/vsr/private/verifiedsoftware-roadmap-2006/Overview

(ii) See the website referenced above, or www.qpq.org/ modules

(iii) Your assessment of the situation is very fair. 